Published as: Ortiz de Gortari, A.B. \& Griffiths, M.D. (2014). Automatic mental processes, automatic actions and behaviours in Game Transfer Phenomena: An empirical self-report study using online forum data. International Journal of Mental Health and Addiction, 12, 432-452.

\title{
Automatic mental processes and behaviours in Game Transfer Phenomena: An empirical self-report study using online forum data
}

\begin{abstract}
Previous studies have demonstrated that the playing of videogames can have both intended and unintended effects. The purpose of this study was to investigate the influence of videogames on players' mental processes and behaviours in day-to-day settings. A total of 1,023 self-reports from 762 gamers collected from online videogame forums were classified, quantified, described and explained. The data include automatic thoughts, sensations and impulses, automatic mental replays of the game in real life, and voluntary/involuntary behaviours with videogame content. Many gamers reported that they had responded - at least sometimes - to real life stimuli as if they were still playing videogames. This included overreactions, avoidances, and involuntary movements of limbs. These experiences lasted relatively short periods of time but in a minority of players were recurrent. The gamers' experiences appeared to be enhanced by virtual embodiment, repetitive manipulation of game controls, and their gaming habits. However, similar phenomena may also occur when doing other non-gaming activities. The implications of these game transfer experiences are discussed.
\end{abstract}

Keywords: Game Transfer Phenomena; videogame effects; cognitive distortions; implicit memory; priming effects. 


\section{Introduction}

The psychosocial and physiological effects of media engagement have been debated for many decades. Studies have demonstrated that the playing of videogames can have both intended (Brown et al., 1997) and unintended effects (Anderson \& Dill, 2000; Beullens, Roe, \& Van den Bulck, 2008). Scholars had speculated that transfer effects may be more pronounced if virtual reality mechanisms become more realistic (e.g., Persky \& Blascovich, 2008; Tamborini et al., 2004), and immersive (Segovia \& Bailenson, 2009). According to Johnson, Hashtroudi and Lindsay (1993), memories from virtual experiences are similar to real world memories because they are rich in perceptual detail (e.g., visual and auditory cues) and that facilitate their recall. The use of realistic cues is now commonplace in many videogames and this may aid associations between videogame elements and real life counterpart stimuli. Therefore, it is important to investigate these transfer effect phenomena with immersive technologies such as videogames.

A considerable amount of literature focusing on the psychosocial effects of videogames has been published. This includes the effects of excessive gaming (e.g., Grusser, Thalemann, \& Griffiths, 2007), the playing of violent videogames (e.g., Anderson, Gentile, \& Buckley, 2007), and the impact of playing videogames on other behaviours such as driving (e.g., Beullens, et al., 2008). Most of these studies have investigated gamers' conscious thoughts and behaviours in specific settings such as traffic accidents after playing racing videogames, or behaving aggressively in the laboratory after playing violent videogames. However, little is known about gamers' unconscious information processing that occurs during the playing of videogames (either immediately after stopping playing, or some time after stopping playing).

A previous study examining Game Transfer Phenomena (GTP) was conducted using an interview study with 42 young Swedish frequent gamers (Ortiz de Gortari, Aronsson, \& Griffiths, 2011). In that study, it was reported that gamers: (i) thought about using videogame elements in real life to solve real life issues, (ii) responded automatically to real life stimuli associated with behaviour that they performed in the videogame, such as gamers feeling the urge to climb buildings, (iii) saw videogame images superimposed on real life objects such as when gamers saw text boxes above peoples' heads as in the videogames they played, and (iv) performed involuntary behaviours such as when a gamer started to dance like his videogame character without any conscious intention of doing so. In addition to these self-reports, 
research examining the physiological side-effects of the exposure to highly immersive environments and simulators has been conducted, such as that focusing on neural adaptation (e.g., motion sickness symptoms) (e.g., Viirre \& Bush, 2002). However, there is a lack of research about (i) the psychological and physiological effects in videogames that do not involve the wearing of head mounted displays, and (ii) the understanding of the psychological implications of these experiences.

Consequently, the purpose of this study was to investigate the influence of videogames on gamers' mental processes and behaviours in day-to-day settings. It was also envisaged that the study would supplement the growing body of literature on the psychosocial implications of videogame playing. More specifically, the present study investigated the influence of videogame playing on gamers' automated mental processes and involuntary responses to real life stimuli (e.g., objects, environments, events, etc.) in daily settings. This was done by examining gamers' phenomenological transfer of experiences from the virtual world of videogames to non-gaming situations in their day-to-day life. Previous research (e.g., Ortiz de Gortari \& Griffiths, 2012) has shown that GTP can manifest as automatic mental processes, altered sensory perceptions, automated actions, and involuntary behaviour. This study focused on two of the five modalities of GTP: automatic thoughts (GTPAT) and voluntary/involuntary behaviours (GTP-B). In this paper, they are simply referred to as 'automatic thoughts and behaviours GTP' (GTP-ATB). Another purpose of the present study was to extend the findings of a previous small-scale GTP interview study (Ortiz de Gortari, et al., 2011) and contribute to the understanding of non-volitional phenomena (e.g., recurrent thoughts, automatic behaviours).

\section{Method}

Participants: A total of 1,023 experiences from 762 gamers from 44 publicly available online videogame discussion forums were collected and classified as GTP-ATB. (Other findings examining other GTP modalities such as visual GTP (Ortiz de Gortari \& Griffiths, 2013) and auditory GTP (Ortiz de Gortari \& Griffiths, in press) have been reported elsewhere). Some online gaming forums were related to specific videogames whereas others were more general gaming forums. A total of 262 different videogames were identified has having been associated with GTB-ATB experiences. Only 172 gamers reported their age ranging in age from 12 to 56 years $(M=20.19, S D=5.71)$ and comprising 191 males and 22 females. 
Procedure and data collection: Gamers' experiences identified as GTP-ATB were extracted from a larger dataset for the analysis in the current study. Some gamers reported more than one GTP-ATB experience. Therefore, the number of experiences is larger than the number of participants in the study. Game genres included: puzzle games, massively multiplayer online role-playing games, and first-person shooter games. Videogame gamers' forums were searched using the Google search engine with the following keywords: "Tetris effect", "bleeding effect AND videogames", "hallucinations videogames", "videogames AND/OR real life/reality". The topics of the online forums included: "suffered the Tetris Effect", "Minecraft Effect”, “Guitar Hero effect”, "Game Transfer Phenomena”, "games stuck in your head", and "videogame persists in real life". The number of posts relating to GTP in each online forum varied. Only posts that contained specific references to GTP were coded and analysed. Ethics approval for the study was granted by the researchers' University Research Ethics Committee.

Data analysis: Thematic analysis was used to code and analyse the data. The first step was to systematically record gamers' experiences in different categories according to the modality that the GTP occurred in (i.e., visual, auditory, thoughts, behaviours). Consequently, gamers' self-reports identified as GTP-ATB were extracted from the categories constructed and coded in a database for a systematic coding and quantification. At this stage, some data were eliminated because some self-reports did not contain enough information and/or were ambiguous. Gamers' self-reports about dreams were also excluded from analysis. Categories and variables in the database were modified until all gamers' experiences were coded under a specific category (e.g., persistent thoughts). Other information that was coded (if provided) included: (i) gamers' profile (nickname, age, gender), (ii) GTPATB characteristics (e.g., frequency of occurrence, duration), (iii) playing habits (e.g., frequency of play, length of playing sessions), (iv) gamers' perception of their GTPATB experiences (e.g., positive, neutral, negative), and (v) content of the experience (e.g., educational, dangerous, criminal).

The data analysis was informed by a rigorous literature review concerning automatic mental process. In addition to this, some videogames identified in the posts were played by the first author. This was to gain a clearer idea of the mechanisms and concepts described by the gamers. This was also supplemented by the watching of gameplay videos that also provided further insight into what gamers were describing. The gamers' self-reports (below) were paraphrased - where possible - to reduce the possibility of individual gamers being 
tracked, and to protect gamers' online identity. This included using synonyms, changing tenses, and/or removing extraneous information. Gamers' pseudonyms were also modified.

\section{Results}

The results are presented in two sections: (i) general characteristics of GTP-ATB, and (ii) types of GTP-ATB identified. The majority of GTP-ATB experiences reported (85\%) were triggered by an association with an external (real life) stimulus.

\section{General characteristics of GTP-ATB}

Only a few posts included information explaining the general characteristics of GTP-ATB.

Gamers' perception about their GTP-ATB experiences $(\boldsymbol{n}=78)$ : More posts $(\mathrm{n}=59)$ included negative expressions about GTP-ATB experiences (e.g., "worry", "unhealthy", "PTSD", "problem", "messed up", "embarrassing", "had to quit playing") than posts that considered GTP-ATB experiences to be normal $(n=3)$ (e.g., "no big deal", "normal", "surprise") or positive ( $\mathrm{n}=13$ ) (e.g., "entertainment", "funny", "good times", "nerdy", "awesome"). Some gamers also referred to GTP-ATB as "weird" and "crazy" (n=22).

Duration of the GTP-ATB experiences $(\boldsymbol{n}=45)$ : GTP-ATB experiences were reported as lasting seconds or minutes $(\mathrm{n}=19)$. In other cases GTP-ATB experiences were reported as lasting hours ( $\mathrm{n}=5$; e.g., "all the night", "for a while"). Some gamers mentioned that GTPATB experiences lasted days or longer ( $=21$; e.g., "several weeks", "over six months", "for years").

Frequency of GTP-ATB occurrence $(n=1,023)$ : The majority of the gamers mentioned that GTP-ATB experiences happened only once or only reported one experience $(n=721)$. However, there were also gamers that experienced GTPATB more than once $(n=237)$, many times $(\mathrm{n}=28)$, or anytime/every time $(\mathrm{n}=36)$.

Hours played per session when having GTP-ATB experiences $(n=147)$ : In most of the cases, the posts included details indicating that the gamers played long sessions $(n=110$; e.g., 3.5 hours) or very long sessions ( $n=37$; e.g., "all the day", and "many hours straight"). A total of 123 gamers' narrations indicated explicitly that they were playing excessively (e.g., "junkie", "too much", "a week no-sleep", "all waking hours", “addicted”, and "days straight").

Activities associated with GTP-ATB experiences $(n=307)$ : The activities mentioned by most gamers associated with experiencing ATB-GTB were: driving $(\mathrm{n}=91)$, walking $(\mathrm{n}=$ 
84), waking up ( $n=18)$, passenger in a vehicle or public transport $(n=13)$, and lying in bed and/or trying to sleep $(n=12)$. Other activities $(n=89)$ included: being passive or bored, talking with others, attending a lecture, listening to music, packing or arranging things, training, reading or surfing the web, typing or writing, and during playing. Additionally, automatic activities such as cooking, getting dressed, taking a shower, washing the dishes, eating, and stressful situations (e.g., fighting, taking a test/exam) were also reported.

Physiological conditions associated with GTP-ATB experiences $(n=14)$ : The conditions associated with GTP-ATB included being sleep deprived, tired, exhausted, sick, feeling dizzy and/or having headache.

Content of the GTP-ATB experiences $(n=298)$ : The content of GTP-ATB experiences was classified as either being: educational, dangerous, or criminal. Educational experiences $(\mathrm{n}=$ 4) included the experience of building something, reflecting about the nature or their own behaviour, and avoiding an accident. Some gamers also used GTP-ATB to strategically analyse and explore real life environments $(n=132)$. Dangerous content $(n=56)$ included "speeding ticket", "side-swipe any car", "tried running on a wall", "leaning into curves"), and criminal content ( $n=40$; e.g., "consider pick-pocketing", "jump out of my car and jack it", and "hitting people with my car". Gamers also reported feeling paranoid or hyper-vigilant (n =67) and reported such things as "everybody is a spy", "afraid of backstabs [in real life]", "observant and cautions", and "paranoid".

\section{Main GTP-ATB categories}

The gamers' GTP-ATB experiences mainly occurred either immediately after stopping playing or some time after stopping playing, with a few occurring while playing. Seven main categories were created based on the data collected: (I) thoughts with videogame content, (II) cognitive errors and distortions influenced by videogame content, (III) subjective sensations of unreality, (IV) urges and impulses to do something as in the videogame, (V) automatic and involuntary mental actions involving videogame content, (VI) carrying out automatic actions, and (VII) behaviours influenced by videogame experiences. Table 1 contains a complete quantification of all the subcategories of GTP-ATB identified based on the online forum data collected.

\section{Involuntary thoughts about videogame content $(n=93)$}


In this category, some gamers' transfer experiences manifested themselves as involuntary thoughts. This category included: (i) persistent involuntary thoughts about videogame content, and (ii) episodic involuntary thoughts about videogame content.

\section{(i) Persistent involuntary thoughts about videogame content}

Here, gamers involuntary kept thinking about the videogame after they had stopped playing. These experiences manifested themselves as: (a) uncontrollable thoughts about the videogame, (b) thoughts that involved strategic thinking from a videogame applied to real life.

\section{(a) Uncontrollable thoughts about the videogame}

Here, the gamers could not stop thinking about the videogame. These thoughts were unwanted and in some cases were unpleasant:

"I cannot stop thinking about Minecraft. It's ruining my life" (Becareli)

(b) Thoughts that involved strategic thinking from a videogame applied to real life

Some gamers also found themselves applying videogame strategies to real life or thinking how they would act in hypothetical scenarios using knowledge from a specific videogame. For instance:

"I kept planning ways to avoid being seen while invisible...Man, I'm messed up" (Cozymed)

"Splinter Cell thinking about what would happen if I were to sneak up behind someone" (Brace)

\section{(ii) Episodic involuntary thoughts about videogame content}

Here, involuntary episodic thoughts were typically elicited by external real life stimuli. This category of experiences was subdivided into: (a) involuntary thoughts about the videogame triggered by external stimuli, and (b) selective attention to external stimuli related to that in the videogame, and (c) worries about losing control and confusing real life with a video game.

(a) Involuntary thoughts about the videogame triggered by external stimuli

In some cases, gamers provided analogies and/or made comparisons between real life stimuli and elements in the videogame. For instance: 
"Every time I hear old school music I think of Fallout 3" (SamuelIX)

(b) Selective attention to external stimuli related to that in the videogame

Here, gamers found themselves paying attention to specific real life stimuli and/or environments relevant to those in a videogame. For instance:

"Since I started playing Minecraft and Dwarf Fortress, I find tiled floors extremely distracting" (Debi08)

(c) Worries about losing control and confusing real life with a video game

Some gamers experienced thoughts about losing control by confusing real life with the videogame. For instance:

"It was scary because I would always worry that if I was tired or not paying attention I would by mistake switch over to Grand Theft Auto IV mode and drive over cars and people" (ChronosBob)

\section{Cognitive errors and distortions influenced by videogame content $(n=178)$}

In this category, many gamers found themselves making judgemental errors when they interpreted real life stimuli with the logic of the videogame or mixed-up real life events and videogame events. This category included: (i) memory errors between real life content and videogame content, (ii) misinterpretation of real life stimuli and events with that in a videogame, (iii) mood modification triggered by stimuli associated with videogame content, and (iv) false expectations in real life based on the content of a videogame.

\section{(i) Memory errors between real life content and videogame content}

Here, gamers made memory errors that led to them confusing real life events and/or objects with experiences from within the videogame. Some gamers claimed that confusion occurred between the information source (e.g., who said what) or memories about the origin of the information (e.g., whether events occurred in-game or outside the game). For instance:

"Once, I stand at store in the lighting bulbs department trying to remember why I needed to buy one. Then I remember I need it for a room in the videogame I was playing" (Draven)

"Sometimes get my Sims mixed up with people. 'remember when you'....oh no, wait, that was my Sim" (Lorela).

(ii) Misinterpretation of real life stimuli and events with that in a videogame 
Here, some gamers interpreted real life events and/or objects using experiences they had encountered in a videogame. For instance:

"After a marathon session of Grand Theft Auto, I was driving and saw a car upside down and thought 'Go! It is going to explode in 5 seconds!'” (Dashlama)

Furthermore, some gamers got surprised that things in real life did not work or look as they did in the videogame. For instance:

"I was freaked out when I went outside and trees were round and not square like the videogame I had been playing" (IneedAce)

(iii) Mood modification triggered by stimuli associated with videogame content

Here, real life events associated with the videogame resulted in some gamers' modifying their mood state. For instance:

"It was foggy and the church's bells stopped. It felt so docile, possibly my most relaxing moment that month...in Silent Hill 1 in the school after the boss fight, you play in hell and then wake up to this foggy, calm astonishing world" (Stormsy)

In a few cases, some gamers felt empowered and thought they were capable of doing things in real life as they could in the videogame. For instance:

"This happens to me all the time. When I played Assassin's Creed 2, I started to think I could climb stuff" (StyleFire)

\section{(iv) False expectations in real life based on the content of a videogame}

Sometimes gamers claimed that they experienced unrealistic expectations or assumed that something that happened in the videogame would happen in real life. These experiences were in many cases triggered by the activities that the gamers were doing when this happened. For instance:

"I had been play Mass Effect 2 for seven hours, my mum walked into the room and said something. I paused for about five seconds looking at her waiting for a wheel of options to appear. Weird" (PricelessWil)

\section{Subjective sensations of unreality $(n=12)$}

Here, gamers experienced subjective experiences of unreality relating to one's sense of self and the outside world (Aardema, O'Connor, Côté, \& Taillon, 2010). These experiences were sub-divided into: (i) in real life, feeling as though they were in the videogame, and (ii) in real life, feeling as though they were a videogame character. 


\section{(i) In real life, feeling as though they were in the videogame}

Here, some gamers felt that in real life they were still in the videogame. For instance:

"I was playing Star Wars: Knights of the Old Republic about four hours straight. When I stood up I had a massive head rush. I thought I was a Jedi in a cave for about five seconds. I was worried that the giant birds in the game's caves were going to attack me. I was confused, and afraid" (Sushy)

One gamer reported that he suddenly connected with the videogame and that his fast reactions learned from a videogame helped him to solve a real life situation effectively:

"Need for Speed 2 helped me through a bad slide on ice. When I hit the ice, my brain immediately went into gaming mode. It felt like I was with the PlayStation controller in my hand...I ended up of the slide" (BirdGal)

\section{(ii) In real life, feeling as though they were a videogame character}

Some gamers felt in real life that they were a videogame character. This was usually triggered by an external stimulus similar to that in a videogame or because they performed an activity in real life similar to that in the videogame. For instance:

"I kind of do this with any game I play too much. But when I played Batman: Arkham Asylum for a long time, and I went to sleep thinking I was Batman" (Neko)

\section{Urges and impulses to do something as in the videogame $(n=115)$}

Here, some gamers experienced urges to do something as they would in the videogame when they encountered real life stimuli that shared characteristics with elements within a videogame or performed certain activities as they would in a videogame. For instance:

"I'm having a really tough time. I played Super Mario Galaxy on the Wii, every time I see something shiny, I want to point out at it and pick it up" (Vivala)

"After playing Katamari Damacy, I had a sudden urge to roll over things. This is not good when you are driving. Rows of orange cones should not look like a golden opportunity” (Panter44).

\section{$V$. Automatic and involuntary mental actions involving videogame content $(n=224)$}

Here, many gamers engaged in automatic and involuntary mental actions where they replayed the videogame inside their heads. These types of mental actions went way beyond simple involuntary thoughts popping into their minds as outlined above. These experiences either 
occurred immediately after stopping playing or were triggered by real life stimuli and involved strategic thinking when gamers found themselves exploring and evaluating real life objects or environments in a strategic way as they would in a videogame. Automatic mental actions involve the observing, monitoring, tracking, and/or assembling of real life objects, and depends upon the videogame content. These experiences appeared to be mainly related with activities in the videogame that required a sequence of actions and were typically associated with repetitive action videogames (e.g., tile puzzle games) or those videogames that featured repetitive activities (e.g., climbing buildings).

\section{(i) Automatic mental actions immediately after stopping playing}

These phenomena appeared to be stereotypical and occurred immediately after stopping playing. Gamers' thoughts appeared to be fixated and had lowered cognitive flexibility to switch from virtual to real life tasks as when occurring with persevering mental states (Van den Linden, Frese, \& Meijman, 2003). Sometimes, real life stimuli acted as triggers, but in other cases their presence appeared to have been incidental. For instance:

"I played Vice City and got all the hidden packages at once. When I quit playing I was looking in the corners of the rooms for hidden packages. It was really odd" (Forlife9)

"Lumines. For sometime I was looking at everything! And trying to see how to drop things correctly for get another square or color" (AnnBeast)

Only examples that included automatic mental actions are described in this section. However, it appeared that under perseverative mental states, gamers experienced other GTP-ATB experiences and are described in later sections.

\section{(ii) Automatic mental actions after some delay in stopping playing}

These types of experience were fairly stereotypical but did not occur immediately after stopping playing. All these experiences were triggered by external stimuli that somehow resembled the videogame's elements, environments, and/or activities in the game. For instance:

"Once I stayed up all night to play Lemmings. The next day, when I was trying to read, I kept trying to figure out how to get the Lemmings across the sentences" (Bluesjazz)

"Anyone ever get the Portal effect? Where you're working out where to place portals, ... and it is not entirely voluntary, you are just half aware of it" (Amanda00). 
In other cases, even though these phenomena initiated automatically, it appeared that after some time, gamers obtained control over their experiences. They then appeared to engage fairly voluntarily in playful replays of the videogame every time they encountered the external stimuli that initially triggered the automatic mental actions, and became a routine. Selective attention to particular stimuli appears to guide gamers' experiences. For instance:

"I do this to this day. I do not actively look for grind combos, but sometimes my eyes will just find and follow some crazy good grind combo. Caused by Pro Skater 3 not 2 though" (Karlypex).

\section{Carrying out automatic actions $(n=397)$}

These experiences included involuntary actions such as involuntary movements or verbal outburst related to video game content. These experiences were further categorised as: (i) carrying out stereotypical motor executions, and (ii) cognitive failures with videogame content.

\section{(i) Carrying out stereotypical motor executions}

These experiences included atypical body movements when the gamers reported moving as they would in the videogame such as strafing (i.e., moving side-ways). This mostly (but not always) occurred immediately after stopping playing. These experiences appeared to have strong components of neural adaptation. For instance:

"Many times! Quake 2, made me literally strafe my way around corners in real life!" (Jamal6)

"I played Megaman one to six. After this, my arms would come up automatically like they were going to push the reload save button. It was actually kind of embarrassing" (cornspeed)

\section{(ii) Cognitive failures with videogame content}

These experiences occurred involuntarily due to failures in controlling impulses and led to different types of slips (e.g., verbal, motor) that were mostly triggered by automatic associations between real life stimuli and elements in the videogame. These manifested as: (a) verbal slips involving videogame content, (b) slips involving manipulation of control devices, and (c) slips involving videogame elements, 
(a) Verbal slips involving videogame content

Here, the gamers said something involuntarily involving videogame content. This included (i) slips of the tongue, and (ii) making a sound or singing without awareness. Sometimes gamers found themselves saying something from the videogame without intending to. For instance:

"I had been playing lots of war games. We had to get the students in a line so I was trying to tell the other teacher to go first and I said 'you take point. I will cover rear'" (Rocksdeal)

"I once had the Tank theme from Leaf for dead as my ringtone, but after it went off in public and I yelled 'TANK!' I changed it' (Glitz)

On other occasions, gamers found themselves reproducing some sound or melody from the videogame without intending to. For instance:

"I haven't played a Zelda game for 2 years...I was looking in the drawers a game. When I found it without even realising I sang the open chest theme" (Twistmax)

(b) Slips involving manipulation of control devices

This sub-category contained experiences where gamers made slips trying to manipulate other devices or other software as they would in playing the videogame. For instance:

"Playing too much World of Warcraft, then looking at pictures online, I try to drag the picture around with my mouse to get a better view" (Soulseptic)

(c) Slips involving videogame elements

Here, gamers thought momentarily about using videogame elements to resolve something in real life, and then realized it was not possible. Sometimes these manifested as (i) automatic thoughts when trying to use videogame elements, but also as involuntary body reflexes when gamers tried to use videogame elements in real life. These experiences were also observed as an attachment to videogame elements. Gamers typically tried to use videogame elements that were used repetitively in the game, and that had a function or provided feedback in the game such as maps, heads-up displays (HUDs), zooming functions, teleports, menus, save options, and/or reload options.

(i) Automatic thoughts when trying to use videogame elements

Here, gamers thought about using the videogames in real life after popping up in gamers' minds. For instance: 
" Never mind I've saved at the last checkpoint...wait what? Quick saved too many times to care" (Intelus)

Sometimes gamers experienced an episodic dissociation when looking for game controls in real life. For instance:

" After playing too much Grant Thief Auto: San Andreas. I was riding my bicycle and I need to brake. I thought: 'where is the RI button for the handbrake'. I got scared when I just understand what had just happened" (Paxel_00)

On other occasions, gamers felt weird not having the ability or the element that they had used in the videogame in real life. For instance:

"After playing Oblivion for the first time 15 hours straight, I became extremely disorientated and extremely confused because there wasn't a bar telling me where my destination was located. I actually got slightly lost that night on the way to my friend's house. Not really a hallucination, but still...weird” (Kepchux)

(ii) Involuntary body reflexes triggered by stimuli associated with videogames

Here, the gamers' thoughts resulted in involuntary body movements of fingers, hands, or arms when gamers tried to use videogame elements in real life. For instance:

"Once, after a marathon Halo 2, I heard a sound far away and I tried to 'zoom in'. My right thumb even moved to where " $B$ " would be in the gamepad" (Megamaxin)

"A friend flung out his arm. He became embarrassed...without thinking he was trying to use the grappling hook from a Quake 2 mod to swing under the bridge" (superpaul)

\section{Behaviours influenced by videogame experiences}

These experiences were not limited to involuntary movements, verbal outbursts or isolated actions with video game contents. Here, gamers got engaged in full performance of behaviours influenced by videogame experiences with more or less executive control. These were further sub-categorised as (i) involuntary behaviours elicited by stimuli associated with the videogame, (ii) change in behaviour due to videogame experiences, and (iii) voluntary behaviours involving videogame content

\section{(i) Involuntary behaviours elicited by stimuli associated with the videogame}

Here, gamers experienced an episodic lack of awareness and performed a behaviour without awareness. These experiences manifested as automatic responses and overreactions to real 
life stimuli that had been simulated in the videogame. It appeared that in these experiences, gamers were either incapable of controlling their impulses and nearly performed something as in the videogame but held back, or actually performed the behaviour as in the videogame. For instance:

"After days of playing Grand Thief Auto 4, I was at the gas station. There were 2 cars by each other, and I thought there would be enough room to squeeze through. I got all the way up to the cars and then realized that this was real life" (Sosa)

\section{(ii) Change in behaviour due to videogame experiences}

Here gamers' behaviour modify due to their video game experiences. These manifest as (a) mood stated influence by video game experiences that resulted in behaviours, (b) avoiding real life elements or events, (c) feeling compelled to do something or say something as in the game, and (d) behaviours where the level of executive control was unknown

(a) Mood stated influence by video game experiences that resulted in behaviours

In these experiences gamers mood states influenced by previous video game experiences resulted in impulsive responses. In some occasions, hyper-vigilant mood states resulted in an overreaction.

"I noticed that after I play for a while, the Phoenix Wright games, my mood becomes a lot more assertive, I tend to think that people have something to hide for an hour or so after played" (FeaturedPoet)

"After 2 days of playing Team Fortress 2 straight, I started to wonder if people were spies...I slapped my friend because he came behind me" (Loremore)

Gamers also overreacted while playing due to their immersion in the game. For instance:

"I played more or less 18 hrs Alien vs. Predator 2 in darkness. My father come in, I turned around and shout swearwords while clicking the trigger of the non-existent gun in my hands...He disconnected the plugs from the PC" (Korma)

\section{(b) Avoiding real life elements or events}

Some gamers avoided specific real life objects or environments because they considered them threatening influenced by their experiences in the games. For instance:

"When I played too much World Ware 2 Online, I always refused to go near churches... I was afraid that French snipers where laying down under the bell, waiting for pull the trigger" (Normax) 
"I avoided water fountains for an hour after I had played Fallout 3 for too long. Then I realized that I was acting really stupid" (darklord22)

(c) Feeling compelled to do something or say something related to the videogame

Here, gamers felt compelled to do something as they did in the videogame or to say something as in the game. Gamers stated that they "had to do it". These types of experiences also manifest as: organizing real life objects as in the game and collecting items related to the videogame. For instance:

"The last time I experienced this and it turned out problematic was when I played too much Mirror's Edge. If I saw something red I had to jump to it or try to run across it" (Josh_66)

On other occasions, the gamers felt the compulsion to say things as in the videogame that later on become in playful outburst with video game contents. These experiences were different than saying something without awareness. For instance:

"Thanks to Mass Effect, there are now certain words I have to say in a 'quarian' accent. 'Migrant', 'Fleet', 'Normandy', 'Engineer'" (Libra)

(d) Behaviours where the level of executive control was unknown

Also, there were other experiences where it was difficult to establish the level of executive control of the gamers. For instance:

"If I have been playing a driving game a lot (Burnout or Daytona), I tend to be a little more aggressive in the highway, and drive a little faster. I start thinking about powersliding when I come to curves, but of course I don't" (peachblue)

\section{(iii) Voluntary behaviours involving videogame content}

Here gamers voluntarily applied videogame contents into their daily lives by (a) doing something inspired by videogame content in real life, (b) telling jokes and repeating phrases from videogames, and (c) mimicking videogames for amusement. This category can be categorized as the playful portray of videogames in real life situations and can be found on places such as YouTube.

(a) Doing something inspired by videogame content in real life

Here, the gamers performed some activity or took a decision inspired by something that happened in the videogame they played. For instance: 
"I tried to remove the pilot light from a stove for garbage for made a shish kebab in Fallout 3" (Bambooman)

\section{(b) Telling jokes and repeating phrases from videogames}

There were also cases were gamers used phrases from the videogames for joking or interacting with others. For instance:

"Once I was in a car with a friend who was driving and I told him if he run over the old lady we would get 30 points" (pax2000)

\section{(c) Mimicking videogames for amusement}

Here, some gamers deliberately imitated video game contents for amusement and to interact with other people. For instance:

"Whenever I'm bored, I will look at people far away and try to rail them. I make a reticule with my hand" (Waffleeater)

\section{Discussion}

The purpose of this study was to investigate the influence of videogames on players' mental processes and behaviours in day-to-day settings, immediately after stopping playing and/or some time after stopping playing. A minority of gamers reported that when GTP-ATB occurred they had been playing intensively, sometimes for days in a row. Excessive gaming has also been reported as a factor in previous GTP studies (Ortiz de Gortari, et al., 2011; Ortiz de Gortari \& Griffiths, 2013). The majority of the experiences identified in this study appeared to occur episodically and last relatively short periods of time. In most of the cases, GTP-ATB were triggered by automatic associations between real life stimuli and stimuli within the videogame. Results also indicated that the majority of GTP-ATB manifested as thoughts and impulses that were within the gamers' control.

The importance of real life stimuli as triggers for GTP have been suggested in previous studies (Ortiz de Gortari, et al., 2011; Ortiz de Gortari \& Griffiths, 2012). In general, GTP-ATB can be considered as a type of ruminative behaviour and preoccupation for the videogame that in some cases can manifest in different ways (e.g., intrusive thoughts, stereotypical mental replays in real life settings). According to cognitive-neoassociation theory, rumination is capable of maintaining thoughts, feelings and behavioural tendencies that are active in semantic memory (Berkowitz, 1990). Previous research has found a 
correlation between rumination and the negative effects of videogame playing. For instance, Bushman and Gibson (2011) reported increased aggression 24 hours after playing a violent videogame in laboratory settings. Research has also found that daydreaming about videogames is positively correlated with problematic gaming (Demetrovics et al., 2012). For this reason, the relationship between GTP and the effects of videogame content (both positive and negative) should be further investigated.

Only a few of the online forum posts included information about what activities gamers were doing at the time of their GTP-ATB experiences. The majority of GTP-ATB experiences occurred in a social context and the activities reported by gamers included being engaged in automated behaviours such as walking, driving, and packing. This finding appears to mirror research into mind wandering (Smallwood \& Schooler, 2006), musical imagery (Hyman et al., 2012), and GTP identified in other modalities (Ortiz de Gortari \& Griffiths, 2013). GTP-ATB also occurred when gamers felt tired, sleep deprived, and stressed. States of anxiety and stress have also been reported in previous GTP studies (Ortiz de Gortari, et al., 2011; Ortiz de Gortari \& Griffiths, 2013). Overall, this study found that GTP-ATB manifested as thoughts, sensations and impulses, automatic mental actions, automatic actions, voluntary and involuntary behaviour with video game content.

More specifically, thoughts about the videogames manifested themselves recurrently or episodically when triggered by external real life stimuli. Sometimes, gamers kept thinking about videogame strategies and creating fictitious scenarios, while on other occasions gamers could not stop thinking about the videogame. While some thoughts appeared to amuse gamers, others were unwanted and intrusive. Thinking obsessively about the gaming (i.e., being totally preoccupied) is considered one of the diagnostic criteria for gambling and gaming addictions (Griffiths, 2002). It is not known from this study how long thoughts persisted in the gamers' minds, but some gamers reported a lack of sleep or concentration. Recurrent and stereotypical visualizations of videogame images that sometimes facilitate insomnia have been previously reported (Ortiz de Gortari \& Griffiths, 2013).

Among some gamers, GTP-ATB manifested themselves as cognitive errors and distortions. Here, irrational thoughts popped up in the gamers' minds when interpreting real life events using the logic from the videogame, making reasoning biases, and expecting that something in real life would happen as in the videogame. For example, gamers expected loading pauses or believed videogame characters, icons, and menus would appear. This is possibly because videogames comprise predictable and repetitive sequences of events. Every action has a consequence, so when something in real life reminded the players of the 
videogame, they applied scripts (i.e., well-structured sequences of events associated with a familiar activity) (Abelson, 1981) from the videogame to interpret, evaluate and react to events (if only momentarily). The presence of hostile expectations after playing an aggressive game has been found experimentally by completing ambiguous stories (Bushman \& Anderson, 2002). The present study demonstrated that gamers' expectations have the capacity to be influenced by the videogame content and by gamers' experiences in the videogame.

Furthermore, some gamers (at least momentarily) assumed that things in real life function as in the videogame. In other cases, gamers experienced omnipotent thoughts such as believing that it was possible to jump up onto the top of buildings easily. According to some research, reinforcement of prohibited acts within a videogame leads to desensitization to real life consequences of prohibited actions (Funk, Baldacci, Pasold, \& Baumgardner, 2004). However, this study suggests that similar effects can also occur when reinforcing positive actions - as long as the associations are established. It was also found that some gamers made memory errors from videogame characters and events with those in real life. Source monitoring errors and false memories have been found in previous research relating to watching films (Roberts \& Blades, 1999), narratives, and virtual worlds (Segovia \& Bailenson, 2009). It could perhaps be speculated that since videogames can elicit emotions, memories can be enhanced that facilitate the occurrence of involuntary memories later on (Berntsen \& Rubin, 2002). I really don’t understand what you mean here

Other types of GTP-ATB were classified as subjective sensations of unreality. Here, the gamers experienced sensations of derealisation and depersonalization that can be triggered by external cues associated with the videogame. Depersonalization and derealisation are on a continuum from normal, everyday cognitive processes to clinical manifestations such as chronic dissociative disorders (Aardema, et al., 2010). Short-lived dissociative experiences such as depersonalization and derealisation, and reduced sense of presence in the physical world, have been correlated with exposure to virtual reality, especially in individuals that are prone to experience dissociation (Aardema, et al., 2010). For instance, Forsyth and colleagues (2001) described a case of a man who was admitted to a psychiatric clinic from prison. He thought he was in a videogame and was trying to collect points while stealing motor vehicles and assaulting the owners with weapons.

The data also suggested that some experiences occurred under perseverative mental states where gamers experienced lowered flexibility to switch from activities in the virtual world to real life. This finding may be explained by the fact that playing a videogame is a cognitively demanding activity, and that playing for prolonged periods of time can result in 
mental fatigue. Perseverative mental states have been correlated with the lack of executive control under mentally fatigued states since automatic processes are triggered by situational or external cues, even when this is inappropriate (Van den Linden, et al., 2003). It could be that being mentally fatigued makes gamers more prone to experiencing GTP-ATB. Such a finding suggests that players should be made aware about the possible effects of prolonged videogame sessions. These experiences manifested as irrational mind popping, involuntary body movements, involuntary behaviours, and automatic mental actions.

Automatic mental actions with videogame content manifested as stereotypical mental replays of the videogame in real life environments. Sometimes these experiences occurred immediately after stopping playing. For instance, some gamers kept trying to mentally combine and fit real life objects as if they were Tetris videogame pieces. At other times, stereotypical mental replays occurred but not necessarily after directly stopping playing, and were triggered by external stimuli. Here, gamers found themselves analysing real life environments and paying attention to exits, spotting places to engage in grinding, and mentally climbing buildings, etc. This confirms the findings of a previous GTP study GTP (Ortiz de Gortari, et al., 2011). Moreover, when gamers found themselves paying attention to real life objects relevant to the videogame, it resulted in 'selective attention'. This is similar to individuals with gaming or alcohol problems that respond more to stimuli related to gaming or alcohol (Cox, Hogan, Kristian, \& Race, 2002; Zhou, Yuan, \& Yao, 2012).

Gamers that experienced stereotypical motor executions appeared to show lower motor flexibility. For instance, some gamers found themselves strafing in corners, with one gamer saying that she walked backwards randomly while another gamer experienced his arms rising automatically as if they were going to push the buttons on the videogame control pad unintentionally. These experiences showed the effects of pushing buttons repeatedly but also demonstrate how simulations of body movements in virtual environments can have similar effects. Previous research has found neural adaptation effects after the exposure to virtual environment simulators such as the reduction of complex psychomotor flexibility, and reduced motor control (e.g.,Champney et al., 2007). The data also suggest that gamers' behaviours have been conditioned to respond in certain way to stimuli and events, and that some gamers experienced difficulty in controlling their impulses. Thus, virtual objects become conditioned stimuli. Because of priming effects, the exposure to a stimulus with a specific meaning facilitates the accessibility of thoughts, feelings, and behaviours associated with the stimulus, and consequently affecting the responses to the stimulus (RoskosEwoldsen, Roskos-Ewoldsen, \& Carpentier, 2002). 
Gamers' automatic responses to real life stimuli manifested differently. Some gamers made slips trying to use videogame elements to resolve real life issues, when videogame elements and activities were associated. This occurred as thoughts or involuntary movements of fingers or arms. These experiences show interesting effects of virtual embodiment and attachment to artificial bodies. Yee and Bailenson (2007) reported the Proteus Effect, i.e., "observations of one's own appearance can lead to behavioural changes" (Yee \& Bailenson, 2009, p.196). Visual illusions of belonging to a rubber hand or someone else's body parts have been experimentally induced (Petkova \& Ehrsson, 2008). In this - and a previous GTP study - gamers reported missing videogame elements in real life (Ortiz de Gortari, et al., 2011). For instance, one gamer that played 15 hours straight got slightly lost when going to a friend's house because he could not see the cursor towards his destination. Interestingly, in a previous GTP study where visual experiences were analysed, gamers' saw images of HUDs and health bars (Ortiz de Gortari \& Griffiths, 2013).

On other occasions, conditioned objects stimulated the urge to do things as in the videogame. For instance, different gamers reported an urge to climb buildings and run red lights while driving. In most cases, the gamers contained (i.e., controlled) their impulses. However, in some cases, the gamers lost executive control and experienced what appeared to be short episodes of lack of awareness or dissociation. For example, gamers said something with unintentional videogame content. Some gamers also overreacted to real life stimuli such as ducking down when they saw a security camera. More serious cases occurred when the gamers' hyper-vigilant mood states resulted in impulsive behaviour (such as when a gamer slapped someone that came from behind them). This also occurred when being highly immersed in the videogame. Some gamers also avoided real life stimuli that became aversive - at least momentarily - due to their videogame experiences. Such experiences can be understood as "conditioned avoidances" (Costello, 1970 p, 254). These responses appear to be of an adaptive nature in avoiding expected harm (as opposed non-adaptive that occur in phobic behaviours).

In the most extreme cases, gamers nearly performed something as in the videogame but stopped at the last minute when they realized that they were in real life. In other cases, gamers carried out harmless involuntary behaviours as in the videogame such as picking up real life objects. Although, there were a few extreme cases such as one gamer that broke a barrel in a store expecting to find bananas so he could get an extra life, other gamers found themselves driving as in the videogame shortly after stopping playing. Involuntary behaviours identified in this study appear to have been automatically triggered, influenced by 
cognitive distortions such as false expectations due to videogame experiences and should not be interpreted as an intention to harm.

The data also showed there were other experiences where the gamers performed actions as in the videogame because they felt compelled to do so. Feeling compelled to do something adheres to the framework of obsessive-compulsive behaviour, even though this was not the case for all gamers (Soutullo, McElroy, \& Goldsmith, 1998). It is speculated that when the videogame or some activity in the videogame become salient, gamers have difficulties in managing their thoughts, and in extreme cases obsessions, so they need to reproduce the activity at some level as a way of reducing the anxiety or distress., Finally, gamers found inspiration in videogame content for doing something in real life and some gamers imitated and mimicked videogame content. This confirms the findings of a previous GTP study where players used videogame content to interact with friends and for amusement (Ortiz de Gortari, et al., 2011). While in most cases imitating or mimicking videogame content appears to have a strong component of executive control, it appears that this was not always the case in this study. Gamers sometimes caught themselves mimicking videogame characters or humming music from the videogames.

Limitations: While the initial findings of this study are promising, a number of limitations need to be considered. First, this study used secondary data (i.e., gamers' selfreports, collected in online videogame forums). This has a number of shortcomings: (i) while the researchers did not influence gamers' self-reports with direct questions, there may have been researcher bias in the selection of gamers' self-reports, (ii) since there were large number of self-reports, it was not possible to clarify the content with the gamers and the interpretation of what was reported was the researchers rather than the participants' view, (iii) the gamers' socio-demographic and psychological profiles were largely unknown and only a few gamers included their age and gender in their posted comments, and (iv) it was not possible to be certain about the veracity of gamers' self-reports. However, this study analysed data from 44 different online videogame forums, and similar experiences have been found in the other GTP studies previously conducted.

Conclusion: In this study, the gamers' GTP-ATB experiences were explained as neural adaptation, perseverative mental states, cognitive distortions, lack of awareness/ dissociations, and source monitoring errors. Although some undoubted positive effects of videogaming were observed and the potential of using videogames as learning tools is evident, some gamers' experiences raise concern. On one hand, gamers' self-reports highlight strategic thinking where gamers explored real life environments or created hypothetical 
scenarios that required planning, critical evaluation of situations, visual spatial abilities in rotating real life objects, tracking objects, and/or when multi-tasking by switching from one task to another (Boot, Kramer, Simons, Fabiani, \& Gratton, 2008). Also, moral thinking and personal boundary testing occurred when urges to do controversial things within-game occurred. Furthermore, these experiences resulted in gamers self-monitoring their playing habits. GTP-ATB provided gamers with additional entertainment value, and helped them in life and/or made them feel more intelligent and/or powerful. On the other hand, some gamers reported experiencing confusion, embarrassment, annoyance, and/or feeling mentally ill. Gamers also engaged in risky behaviours such as driving like they did in videogames. Additionally, some of the gamers' overreacted and avoided real life stimuli and events, and reported becoming suspicious in real life environments.

The data suggest that top-down processing was influenced by intensive gaming that compromised the reasoning and behaviour of some gamers in real life (at least momentarily), mainly when automatic associations between videogame activities and real life stimuli were established. The transfer of virtual experiences to the real life in many cases appeared to depend upon the affordances found in real life environments that first triggered the associations (facilitated by simulations of real life objects in the game environment), and secondly, provided the possibility of actually performing videogame activities (or not) in real life. Harmless activities with video game content were sometimes better acted out, while dangerous and controversial acts were sometimes repressed.

The findings in this study should be interpreted carefully and should not be generalized. Indeed, in this study, gamers reported similar experiences in the same games, as as reported in previous GTP studies (Ortiz de Gortari, et al., 2011; Ortiz de Gortari \& Griffiths, 2013), and confirms the relevance of videogame content in gamers' experiences. However, it is important to note that GTP-ATB manifested after playing games with different content, and that more systematic research is needed to make definitive statements about particular behaviours and their further implications. Furthermore, similar phenomena to those identified in this study have also been experienced by engaging intensively in other nongaming activities (e.g., watching movies, repetitive activities, etc.). However, particular phenomena appear to be enhanced by the virtual embodiment and the repetitive manipulation of videogame controls and, gamers' habits (e.g., frequent and prolonged exposure). It is speculated that gamers are more prone to manifest stronger responses in front of real life stimuli associated with the videogame immediately after stopping playing under perserverative mental states or during playing. The levels of response may depend of the 
gamers' personality characteristics and/or level of immersion. Individuals with pathological personality traits and/or ones with poor impulse control may be more prone to experience the negative effects of GTP-ATB by not controlling their impulses when not discriminating between real life stimuli and videogame situations.

A large number of studies examining media effects have showed a correlation between videogame playing and subsequent effects. This study - by contrasting gamers' experiences with videogame content - suggests that there may a causal relationship between gamers' GTP-ATB experiences and videogame content. However, other factors may play an important role in triggering gamers' experiences. Further work needs to examine which individuals are more susceptible to experience GTP-ATB and to establish whether experiencing GTP-ATB has long-term cognitive, psychophysiological, and psychosocial effects. Symptoms such as disorientation tend to reduce with the prolonged and repetitive exposure to virtual environments simulators (Stanney \& Kennedy, 1998), and may be the case in some of the GTP-ATB experiences. It is important to inform gamers about how to identify and interpret the GTP phenomena they experience.

\section{References}

Aardema, F., O'Connor, K., Côté, S., \& Taillon, A. (2010). Virtual Reality Induces Dissociation and Lowers Sense of Presence in Objective Reality. CyberPsychology, Behavior \& Social Networking, 13(4), 429-435.

Abelson, R. P. (1981). Psychological status of the script concept. American Psychologist, 36, 715-729.

Anderson, C. A., \& Dill, K. E. (2000). Video games and aggressive thoughts, feelings, and behavior in the laboratory and in life. Journal of personality and social psychology, 78(4), 772-790.

Anderson, C. A., Gentile, D. A., \& Buckley, K. E. (2007). Violent video game effects on children and adolescents: Theory, research, and public policy. New York ; Oxford: Oxford University Press.

Berkowitz, L. (1990). On the formation and regulation of anger and aggression: A cognitiveneoassociationistic analysis. American Psychologist, 45(4), 494-503.

Berntsen, D., \& Rubin, D. C. (2002). Emotionally Charged Autobiographical Memories Across the Life Span: The Recall of Happy, Sad, Traumatic, and Involuntary Memories. Psychology \& Aging, 17(4), 636. 
Beullens, K., Roe, K., \& Van den Bulck, J. (2008). Video games and adolescents' intentions to take risks in traffic. [Research Support, Non-U.S. Gov't]. The Journal of adolescent health : official publication of the Society for Adolescent Medicine, 43(1), 87-90.

Beullens, K., Roe, K., \& Van den Bulck, J. (2011). Excellent gamer, excellent driver? The impact of adolescents' video game playing on driving behavior: a two-wave panel study. [Research Support, Non-U.S. Gov't]. Accident; analysis and prevention, 43(1), $58-65$.

Boot, W. R., Kramer, A. F., Simons, D. J., Fabiani, M., \& Gratton, G. (2008). The effects of video game playing on attention, memory, and executive control. Acta Psychologica, 129(3), 387-398.

Brown, S. J., Lieberman, D. A., Gemeny, B. A., Fan, Y. C., Wilson, D. M., \& Pasta, D. J. (1997). Educational video game for juvenile diabetes: results of a controlled trial. Informatics for Health and Social Care, 22(1), 77-89.

Bushman, B. J., \& Anderson, C. A. (2002). Violent Video Games and Hostile Expectations: A Test of the General Aggression Model. Personality and Social Psychology Bulletin, 28(12), 1679-1686.

Bushman, B. J., \& Gibson, B. (2011). Violent Video Games Cause an Increase in Aggression Long After the Game Has Been Turned Off. Social Psychological and Personality Science, 2(1), 29-32.

Champney, R. K., Stanney, K. M., Hash, P. A., Malone, L. C., Kennedy, R. S., \& Compton, D. E. (2007). Recovery from virtual environment exposure: expected time course of symptoms and potential readaptation strategies. [Research Support, U.S. Gov't, NonP.H.S.]. Human factors, 49(3), 491-506.

Costello, C. G. (1970). Dissimilarities between conditioned avoidance responses and phobias. Psychological review, 77(3), 250-254.

Cox, W. M., Hogan, L. M., Kristian, M. R., \& Race, J. H. (2002). Alcohol attentional bias as a predictor of alcohol abusers' treatment outcome. Drug and alcohol dependence, 68(3), 237-243.

Demetrovics, Z., Urbán, R., Nagygyörgy, K., Farkas, J., Griffiths, M. D., Pápay, O., . . Oláh, A. (2012). The Development of the Problematic Online Gaming Questionnaire (POGQ). PloS one, 7(5), e36417.

Funk, J. B., Baldacci, H. B., Pasold, T., \& Baumgardner, J. (2004). Violence exposure in real-life, video games, television, movies, and the internet: is there desensitization? Journal of adolescence, 27(1), 23-39. 
Griffiths, M. (2002). Gambling and gaming addictions in adolescence. Oxford: BPS Blackwell.

Grusser, S. M., Thalemann, R., \& Griffiths, M. D. (2007). Excessive computer game playing: evidence for addiction and aggression? Cyberpsychology \& behavior : the impact of the Internet, multimedia and virtual reality on behavior and society, 10(2), 290-292.

Hyman, I. E., Burland, N. K., Duskin, H. M., Cook, M. C., Roy, C. M., McGrath, J. C., \& Roundhill, R. F. (2012). Going Gaga: Investigating, Creating, and Manipulating the Song Stuck in My Head. Applied Cognitive Psychology, n/a-n/a.

Jean, G. V. (2010). Spy Game to Help Rehabilitate Veterans Suffering From Brain Injuries. [Article]. National Defense, 95(685), 48-49.

Johnson, M. K., Hashtroudi, S., \& Lindsay, D. S. (1993). Source monitoring. Psychological bulletin, 114(1), 3-28.

Ortiz de Gortari, A. B., Aronsson, K., \& Griffiths, M. D. (2011). Game Transfer Phenomena in video game playing: A qualitative interview study. International Journal of Cyber Behavior, Psychology and Learning, 1(3), 15-33.

Ortiz de Gortari, A. B., \& Griffiths, M. D. (2012). An Introduction to Game Transfer Phenomena in Video Game Playing. In J. I. Gackenbach (Ed.), Video Game Play and Consciousness. NY: Nova Publisher.

Ortiz de Gortari, A. B., \& Griffiths, M. D. (2013). Altered visual perception in Game Transfer Phenomena: An empirical self-report study. International Journal of Human Computer Interaction.DOI: 10.1080/10447318.2013.839900

Persky, S., \& Blascovich, J. (2008). Immersive Virtual Video Game Play and Presence: Influences on Aggressive Feelings and Behavior. [Article]. Presence: Teleoperators \& Virtual Environments, 17(1), 57-72.

Petkova, V. I., \& Ehrsson, H. H. (2008). If I Were You: Perceptual Illusion of Body Swapping. PloS one, 3(12), e3832.

Roberts, K. P., \& Blades, M. (1999). Children's Memory and Source Monitoring of Real-Life and Televised Events. Journal of Applied Developmental Psychology, 20(4), 575-596.

Roskos-Ewoldsen, D. R., Roskos-Ewoldsen, B., \& Carpentier, F. R. D. (2002). Media priming: A synthesis.

Segovia, K. Y., \& Bailenson, J. N. (2009). Virtually true: Children's acquisition of false memories in virtual reality. Media Psychology. Media Psychology, 12, 371-391. 
Smallwood, J., \& Schooler, J. W. (2006). The restless mind. Psychological bulletin, 132(6), 946-958.

Soutullo, C. A., McElroy, S. L., \& Goldsmith, R. J. (1998). Cravings and irresistible impulses: similarities between addictions and impulse control disorders. Psychiatric Annals, 28, 592-600.

Stanney, K. M., \& Kennedy, R. S. (1998). Aftereffects from virtual environment exposure: How long do they last? Proceedings of the Human Factors and Ergonomics Society Annual Meeting, 42(21), 1476-1480.

Tamborini, R., Eastin, M. S., Skalski, P., Lachlan, K., Fediuk, T. A., \& Brady, R. (2004). Violent Virtual Video Games and Hostile Thoughts. [Article]. Journal of Broadcasting \& Electronic Media, 48(3), 335-357.

Van den Linden, D., Frese, M., \& Meijman, T. F. (2003). Mental fatigue and the control of cognitive processes: effects on perseveration and planning. [Research Support, NonU.S. Gov't]. Acta Psychologica, 113(1), 45-65.

Viirre, E., \& Bush, D. (2002). Direct effects of virtual enviroments on users. In K. M. Stanney (Ed.), Handbook of virtual environments: Design, Implementation, and Applications (pp. 581-588). Mahwah, NJ: Lawrence Erlbaum Associates.

Yee, N., \& Bailenson, J. N. (2007). The Proteus Effect: The Effect of Transformed SelfRepresentation on Behavior. Human Communication Research, 33, 271-290.

Yee, N., \& Bailenson, J. N. (2009). The Difference Between Being and Seeing: The Relative Contribution of Self-Perception and Priming to Behavioral Changes via Digital SelfRepresentation. Media Psychology, 12(2), 195-209.

Zhou, Z., Yuan, G., \& Yao, J. (2012). Cognitive Biases toward Internet Game-Related Pictures and Executive Deficits in Individuals with an Internet Game Addiction. PloS one, $7(11)$, e48961. 
Table 1. GTPATB categories and sub-categories

\begin{tabular}{|c|c|c|c|}
\hline Type of GTPATB & $\begin{array}{l}\text { Number of } \\
\text { experiences }\end{array}$ & $\begin{array}{c}\text { GTP- } \\
\text { ATB } \\
\text { Type } \\
\%\end{array}$ & $\begin{array}{l}\text { GTP-ATB } \\
\text { category }\end{array}$ \\
\hline \multicolumn{4}{|l|}{ I. Involuntary thoughts about videogame content } \\
\hline \multicolumn{4}{|l|}{ (i).Persistent involuntary thoughts about the game } \\
\hline Uncontrollable thoughts about videogame content & 30 & & \\
\hline $\begin{array}{l}\text { Thoughts that involved strategic thinking from a videogame } \\
\text { applied to real life }\end{array}$ & ne & & \\
\hline \multicolumn{4}{|l|}{ (ii).Episodic involuntary thoughts about videogame content } \\
\hline $\begin{array}{l}\text { Involuntary thoughts about the game triggered by external } \\
\text { stimuli }\end{array}$ & Ial & & \\
\hline $\begin{array}{l}\text { Selective attention to external stimuli related to the } \\
\text { videogame }\end{array}$ & 30 & & \\
\hline $\begin{array}{l}\text { Worries about losing control and confusing real life with a } \\
\text { videogame }\end{array}$ & 4 & & \\
\hline Subtotal & 96 & & \\
\hline \multicolumn{4}{|c|}{ II. Cognitive errors and distortions influenced by videogame content } \\
\hline Memory errors between real life content and videogame content & \begin{tabular}{l|l} 
nt & 28 \\
\end{tabular} & 16 & \\
\hline $\begin{array}{l}\text { Misinterpretation of real life stimuli and events with that in a } \\
\text { videogame }\end{array}$ & a & 36 & \\
\hline $\begin{array}{l}\text { Mood modification triggered by stimuli associated with } \\
\text { videogame content }\end{array}$ & th & 8 & \\
\hline $\begin{array}{l}\text { False expectations in real life based on the content of a } \\
\text { videogame }\end{array}$ & $\mathrm{a}$ & 40 & \\
\hline Subtotal & 178 & & \\
\hline \multicolumn{4}{|l|}{ III. Subjective sensations of unreality } \\
\hline In real life, feeling as though they were in the videogame & 8 & 67 & \\
\hline In real life, feeling as though they were a videogame character & 4 & 33 & \\
\hline Subtotal & 12 & & \\
\hline IV. Urges and impulses to do something as in the videogame & \begin{tabular}{l|l|} 
ne & 114 \\
\end{tabular} & & \\
\hline \multicolumn{4}{|c|}{ V. Automatic and involuntary mental actions involving video game content } \\
\hline Automatic mental actions immediately after stopping playing & 17 & 8 & \\
\hline Automatic mental actions after some delay in stopping playing & 208 & 92 & \\
\hline Subtotal & 225 & & \\
\hline
\end{tabular}




\begin{tabular}{|c|c|c|c|}
\hline \multicolumn{4}{|l|}{ VI. Carrying out automatic actions } \\
\hline (i). Carrying out stereotypical motor executions & 13 & 5 & \\
\hline \multicolumn{4}{|l|}{ (ii). Cognitive failures with videogame content } \\
\hline \multicolumn{4}{|l|}{ a. Verbal slips involving videogame content } \\
\hline Slips of the tongue & 23 & & \\
\hline Making a sound or singing without awareness & 3 & & \\
\hline b. Slips involving manipulation of control devices & 5 & & \\
\hline \multicolumn{4}{|l|}{ c. Slips involving videogame elements } \\
\hline Automatic thoughts when trying to use videogame elements & 161 & & \\
\hline $\begin{array}{l}\text { Involuntary body reflexes triggered by stimuli associated } \\
\text { with videogames }\end{array}$ & 26 & & \\
\hline Subtotal & 231 & & \\
\hline \multicolumn{4}{|l|}{ VII. Behaviours influenced by videogame experiences } \\
\hline \multicolumn{4}{|l|}{$\begin{array}{l}\text { Involuntary behaviours elicited by stimuli associated with the } \\
\text { videogame }\end{array}$} \\
\hline Nearly performing an action triggered by associated stimuli & 15 & & \\
\hline $\begin{array}{l}\text { Performed of behaviours elicited by stimuli associated } \\
\text { with the game }\end{array}$ & 21 & & \\
\hline $\begin{array}{c}\begin{array}{c}\text { Overreactions to real life stimuli due to videogame } \\
\text { experiences }\end{array} \\
\end{array}$ & 27 & & \\
\hline Involuntary mimicking & 13 & & \\
\hline Subtotal & 76 & & \\
\hline \multicolumn{4}{|l|}{ Change in behaviour due to videogame experiences } \\
\hline \multicolumn{4}{|l|}{$\begin{array}{l}\text { Mood stated influence by videogame experiences that } \\
\text { resulted in behaviours }\end{array}$} \\
\hline Avoiding real life elements or events & 7 & & \\
\hline $\begin{array}{l}\text { Feeling compelled to do something or say something related } \\
\text { to the videogame }\end{array}$ & 38 & & \\
\hline $\begin{array}{l}\text { Behaviours where the level of executive control was } \\
\text { unknown }\end{array}$ & 12 & & \\
\hline Subtotal & $?$ & & \\
\hline \multicolumn{4}{|l|}{ Voluntary behaviours involving videogame content } \\
\hline Doing something inspired by videogame content & 9 & & \\
\hline Telling jokes and repeating phrases from videogames & 8 & & \\
\hline Mimicking videogames for amusement & 12 & & \\
\hline Subtotal & 29 & & \\
\hline Total & $\mathbf{1 , 0 2 3}$ & & \\
\hline
\end{tabular}

